\title{
Respiratory muscle function in interstitial lung disease
}

\author{
Stephan Walterspacher ${ }^{1}$, Daniel Schlager ${ }^{1}$, David J. Walker ${ }^{1}$, \\ Joachim Müller-Quernheim', Wolfram Windisch² and Hans-Joachim Kabitz' \\ Affiliations: 'Dept of Pneumology, University Hospital Freiburg, Freiburg, ${ }^{2}$ Dept of Pneumology, Kliniken der \\ Stadt Köln gGmbH, Cologne, and Academic Hospital of the University of Witten/Herdecke, Witten, Germany.
}

Correspondence: H-J. Kabitz, University Hospital Freiburg, Dept of Pneumology, Killianstr. 5, 79106 Freiburg, Germany. E-mail: hans-joachim.kabitzQuniklinik-freiburg.de

ABSTRACT Interstitial lung diseases limit daily activities, impair quality of life and result in (exertional) dyspnoea. This has mainly been attributed to a decline in lung function and impaired gas exchange. However, the contribution of respiratory muscle dysfunction to these limitations remains to be conclusively investigated.

Interstitial lung disease patients and matched controls performed body plethysmography, a standardised 6-min walk test, volitional tests (respiratory drive $\left(P_{0.1}\right)$, global maximal inspiratory mouth occlusion pressure $(P \operatorname{Imax})$, sniff nasal pressure $(\mathrm{Sn} P$ na) and inspiratory muscle load) and nonvolitional tests on respiratory muscle function and strength (twitch mouth and transdiaphragmatic pressure during bilateral magnetic phrenic nerve stimulation (TwPmo and TwPdi)).

25 patients and 24 controls were included in the study. PImax and SnPna remained unaltered (both $\mathrm{p}>0.05$ ), whereas $P 0.1$ and the load on the inspiratory muscles were higher (both $\mathrm{p}<0.05$ ) in interstitial lung disease patients compared with controls. TwPmo and TwPdi were lower in interstitial lung disease patients (mean \pm SD TwPmo $0.86 \pm 0.4$ versus $1.32 \pm 0.4, \mathrm{p}<0.001$; TwPdi $1.34 \pm 0.6$ versus $1.88 \pm 0.5, \mathrm{p}=0.022$ )

Diaphragmatic force generation seems to be impaired in this cohort of interstitial lung disease patients while global respiratory muscle strength remains preserved. Central respiratory drive and the load imposed on the inspiratory muscles are increased. Whether impaired respiratory muscle function impacts morbidity and mortality in interstitial lung disease patients needs to be investigated in future studies.

@ERSpublications

Diaphragmatic muscle function is impaired in ILD while global respiratory muscle strength remains preserved http://ow.ly/lifmy 


\section{Introduction}

The term chronic interstitial lung disease (ILD) comprises a number of different forms, with idiopathic pulmonary fibrosis (IPF) being the most common [1]. IPF is associated with a very poor prognosis, with a median survival time of only 2-3 years after diagnosis [2]. ILD is also known to be associated with limitations in daily activities and impaired quality of life [2]. One of the most troublesome burdens for ILD patients is dyspnoea during exercise, which extends to the resting state as the disease advances [3]. The two most important factors that underlie the development of dyspnoea are suggested to be a progressive decline in total lung capacity (TLC) and vital capacity, along with impairment of diffusion capacity and subsequent development of (primarily hypoxic) respiratory failure [2]. There is increasing evidence that dyspnoea and impaired exercise capacity in ILD might, at least in part, be related to respiratory muscle dysfunction [4-7], although some studies have reported nonaltered respiratory muscle function in ILD patients $[8,9]$.

It is important to note that studies exclusively using volitional tests to assess respiratory muscle function share one major limitation; namely, that they rely on the patient exerting a genuine maximal effort [10]. This means that values below the pathological cut-off may be biased by submaximal efforts. Therefore, the inclusion of nonvolitional tests is required in order to make a definitive diagnosis of impaired respiratory muscle strength.

To this end, the present study aimed to investigate respiratory muscle strength by the use of both volitional and nonvolitional tests, including gold standard bilateral anterior magnetic phrenic nerve stimulation (BAMPS) [10]. In addition, CC chemokine ligand 18 (CCL18), a biomarker that has been shown to be linked to survival in ILD patients, was assessed and correlated to physiological measures [11].

\section{Material and methods}

The study design has been approved by the Institutional Ethics Committee of the University Hospital Freiburg, Freiburg, Germany, and was performed in accordance with the ethical standards laid down in the Declaration of Helsinki. All subjects gave their written informed consent. The study was registered at the German Clinical Trials Register with the identifier number DRKS00000817.

\section{Subjects}

25 patients were consecutively recruited from the Dept of Pneumology at the University Hospital Freiburg, after histopathological confirmation of a distinct form of ILD.

Patients with systemic infections (C-reactive protein $>5 \mathrm{mg} \cdot \mathrm{L}^{-1}$ ), obstructive pulmonary disorders, thoracic skeletal abnormalities, neuromuscular disorders or orthopaedic limitations in walking were excluded from the study. In addition, 24 healthy subjects well-matched for sex, age and body mass index served as controls.

20 patients received individually tailored medication therapy for ILD as follows. Oral corticosteroids $(n=19$, dose range: 7.5-30 mg prednisolone equivalents per day; $\mathrm{n}=1$, dose: $100 \mathrm{mg}$ prednisolone equivalents per day), oral azathioprine $(n=3$, dose range: $10-50 \mathrm{mg}$ per day; $n=5$, dose range: $100-150 \mathrm{mg}$ per day), intermittent intravenous cyclophosphamide $(n=2)$ and methotrexate $(n=1,7.5 \mathrm{mg}$ per week). Patients with hypoxic respiratory failure received long-term supplemental oxygen therapy in line with current recommendations $[2,12]$.

\section{Body plethysmography and exercise testing}

Body plethysmography was performed on all participants (MasterLab; CareFusion, Hoechberg, Germany) based on current recommendations [13] and reference values according to MATTHYs et al. [14]. Subjects refrained from using bronchodilating drugs for at least $12 \mathrm{~h}$ prior to the measurements. Diffusion capacity of the lung was assessed by the single-breath determination of carbon monoxide uptake [15].

A standardised 6-min walk test (6MWT) was performed in line with recent recommendations [16]. Ratings of perceived exertion for dyspnoea and limb discomfort were assessed immediately before and after walking using the modified Borg scale [17]. Blood gases (cobas b221; Roche Diagnostics, Grenzach-Wyhlen, Germany) and blood lactate (SuperGL, Hitado Diagnostic Systems, Möhnensee, Germany) were measured from the arterialised earlobe immediately before and after the 6MWT. Patients under long-term oxygen therapy performed the $6 \mathrm{MWT}$ while receiving corresponding flow rates of supplemental oxygen.

\section{Respiratory and peripheral muscle testing}

All tests on respiratory muscle function were performed in accordance with recent guidelines [10]. All participants were naive to magnetic phrenic nerve stimulation and the experimental setting. All tests were performed by an experienced operator. All subjects were individually instructed for each test procedure and encouraged to achieve maximal efforts if applicable to the test procedure. 
All subjects underwent testing in a standardised sitting position using a flanged mouthpiece and noseclip (except for sniff measurements). All pressures and airflows were recorded by a differential pressure transducer and pneumotachograph (ZAN 400, ZAN 100; nSpire Health, Oberthulba, Germany). To prevent glottic closure during maximal inspiratory/expiratory efforts, a standardised leakage was introduced into the system (length $4 \mathrm{~cm}$, inner diameter $1 \mathrm{~mm}$ ) [10].

\section{Volitional tests of respiratory muscle function}

Respiratory drive was estimated from the mouth occlusion pressure $0.1 \mathrm{~s}$ after the onset of inspiration $\left(P_{0.1}\right)$ and measured during quiet breathing $[18,19]$. Seven random occlusions of the airway to which the subject was blinded were applied and assessed. $P_{0.1}$ is given as the mean value [10].

Maximal static inspiratory mouth occlusion pressure (PImax) was measured from residual lung volume, and peak pressures are reported $[10,20]$. At least five tests were performed. Tests were accepted if 1 ) a maximal effort was observed by the operator; 2) the pressure level was sustained for at least $1 \mathrm{~s}$; and 3) the highest three values differed by $<10 \%$. The absolute maximal value is reported in each case.

Maximal static expiratory mouth occlusion pressure (PEmax) was assessed from TLC [10]. The test was performed analogously to the PImax manoeuvre with comparable test criteria.

Sniff nasal pressure ( $\mathrm{Sn} P \mathrm{na}$ ) was assessed at functional residual capacity [10]. SnPna was measured through a foam-plug (ATMOS MedizinTechnik, Lenzkirch, Germany). The sniff probe was inserted in the nostril that subjectively showed the best airflow, while the sniff manoeuvre was carried out through the contralateral nostril. At least five tests were performed. Tests were accepted if 1) a maximal effort was observed by the operator; 2) the sniff manoeuvre lasted $<500 \mathrm{~ms}$; and 3) the highest three values differed by $<10 \%$. The absolute maximal value is reported in each case.

Nonvolitional tests of respiratory muscle strength

Twitch mouth and transdiaphragmatic pressures (TwPmo and TwPdi) were assessed during BAMPS at maximal stimulator output (100\%) using two coupled stimulators (Magstim 2002; Magstim, Whitland, UK) with two 45-mm figure-of-eight coils (Magstim) [10]. An automated triggering technique was applied, as described previously in detail $[21,22]$. In brief, an inspiratory pressure trigger set at $0.5 \mathrm{kPa}$ was used. Triggering started during quiet breathing at functional residual capacity. Twitches were not accepted if mouth pressure was $>0.75 \mathrm{kPa}$ (50\% above trigger criterion) and if the volume change exceeded $60 \mathrm{~mL}$ upon triggering. Five measurements of TwPmo (and of respective TwPdi) that adhered to the trigger criteria were collected. The highest and lowest values were discarded and the mean of the remaining three measurements is provided in the results section. Twitch pressure recordings were also carefully checked for no change in oesophageal pressure swings at the time of magnetic stimulation. In the event that oesophageal pressure indicated a change from baseline levels, the corresponding twitch pressure assessment was rejected.

To avoid twitch potentiation, a 15-min resting period was maintained prior to magnetic stimulation [23]. As BAMPS has repeatedly been demonstrated to achieve supramaximal phrenic nerve stimulation in most occasions, this parameter was not re-tested in the present study and all twitch pressures were assessed at maximal output $(100 \%)$ of the magnetic stimulators $[24,25]$. TwPdi was recorded after insertion of a double balloon catheter (ZAN; nSpire Health) [10, 21, 22]. Transdiaphragmatic pressures were calculated by subtraction of twitch oesophageal pressures from twitch gastric pressures following BAMPS. The time span between trigger impulse and the pressure maximum of TwPmo (ttrig-max) was automatically assessed and used as a surrogate for phrenic nerve conduction time (i.e. higher values for trig-max indicate a pronounced delay between nerve stimulation and diaphragmatic contraction).

Peripheral muscle strength was assessed by hand-grip force (Martin Vigorimeter; Gebrueder Martin GmbH, Tuttlingen, Germany).

\section{Laboratory investigations}

A venous blood sample was drawn prior to the study from the seated patient and CCL18 concentration was measured using a DuoSet ELISA Development System kit (R\&D Systems Europe, Abingdon, UK) with a detection limit of $7 \mathrm{ng} \cdot \mathrm{mL}^{-1}$. CCL18 values of $<45 \mathrm{ng} \cdot \mathrm{mL}^{-1}$ were considered to be normal [11]. CCL18 concentration was assessed because it was previously reported that compromised survival in patients with IPF is linked to elevated CCL18 values [11].

\section{Statistical analysis}

Statistical analysis was performed using SigmaPlot 11.2 (Systat, Point Richmond, CA, USA). The null hypothesis $(\mathrm{H} 0)$ was defined as no difference between ILD patients and controls in the mean TwPmo. According to the sample size determination (unpaired t-test, expected difference $0.3 \mathrm{kPa}$, power 0.8 , two-sided 
type I error 0.05), Ho can be rejected with 23 participants in each group, based on an estimated standard deviation of $0.35 \mathrm{kPa}$ for TwPmo [26, 27].

Data were analysed for normal distribution prior to further statistical calculations. Normally distributed data are presented as mean $\pm S D$ and non-normally distributed data are presented as median with interquartile ranges. Statistical significance was assumed when $\mathrm{p}<0.05$. The unpaired t-test (normally distributed data) or Mann-Whitney rank-sum test (non-normally distributed data) was used for comparing the two groups. Sex differences between groups were calculated using the Fisher's exact test. Before and after comparisons within the same group were performed by the paired t-test (normally distributed data) or the Mann-Whitney rank-sum test (non-normally distributed data). When comparing more than two groups, one-way ANOVA was used. Correlations were analysed using the Pearson product moment correlation.

\section{Results}

Anthropometric and lung function data for all participants are provided in table 1. Diffusing capacity of the lung for carbon monoxide was measured at $4.02 \pm 1.9 \mathrm{mmol} \cdot \mathrm{min}^{-1} \cdot \mathrm{kPa}^{-1}$ in ILD patients. The classification of ILD was as follows: usual interstitial pneumonia $(n=16)$, nonspecific interstitial pneumonia $(n=3)$, extrinsic allergic alveolitis $(n=1)$, acute interstitial pneumonia $(n=1)$ and not further specified $\operatorname{ILD}(n=4)$. None of the patients suffered from inflammatory myopathies or systemic diseases that are known to directly affect the respiratory muscles (e.g. dermato-polymyositis). 14 patients were on long-term oxygen therapy due to hypoxic respiratory failure. The results from the $6 \mathrm{MWT}$ are presented in table 2. All patients presented with higher levels of exertional dyspnoea compared to limb discomfort at the termination of exercise $(\mathrm{p}=0.03)$.

Indices of muscle function are presented in table 3. Peripheral muscle strength, as assessed by hand-grip force in line with PImax, PEmax and SnPna, were not different between patients and controls (table 3 and fig. 1 , respectively). $P_{0.1}$ was higher in patients compared to controls, while respiratory capacity $\left(P_{0.1} / P_{\operatorname{Imax}}\right)$ was reduced (table 3). Furthermore, the load imposed on the inspiratory muscles, as assessed by the specific inspiratory impedance $\left(P_{0.1} \times \mathrm{t} / \mathrm{VT}\right)$, was higher in ILD patients (table 3$)$. Interestingly, nonvolitional assessment of respiratory muscle strength by the use of TwPmo and TwPdi during BAMPS revealed a highly statistically significant difference, with lower values for ILD patients in comparison to healthy control subjects (table 3 and fig. 2, respectively).

Results from CCL18 measurements $(\mathrm{n}=23)$ are shown in table 4 and disclosed 10 patients with CCL18 values $<150 \mathrm{ng} \cdot \mathrm{mL}^{-1}$ and 13 patients with CCL18 values $>150 \mathrm{ng} \cdot \mathrm{mL}^{-1}$. For the latter high-risk cohort, subgroup analysis revealed that CCL18 correlated with $P_{0.1}(\mathrm{r}=0.61 ; \mathrm{p}<0.001)$ and was inversely related to the 6-min walking distance $(\mathrm{r}=-0.72 ; \mathrm{p}<0.001)$. No such correlation was observed in patients with CCL18 values $<150 \mathrm{ng} \cdot \mathrm{mL}^{-1}$ (low-risk cohort, all $\mathrm{p}>0.05$ ). Furthermore, PImax values were higher in patients with CCL18 $>150 \mathrm{ng} \cdot \mathrm{mL}^{-1}$ compared with those with CCL18 $<150 \mathrm{ng} \cdot \mathrm{mL}^{-1}(\mathrm{p}=0.003)$.

TABLE 1 Anthropometric and lung function parameters

\begin{tabular}{lccc} 
& ILD & Controls & p-value \\
\hline Subjects & 25 & 24 & \\
Male/female & $22 / 3$ & $17 / 7$ & 0.53 \\
Age years & $66(55-70)$ & $61(55-65)$ & 0.1 \\
BMI kg:m m $^{-2}$ & $26.5 \pm 3.6$ & $26 \pm 3.6$ & 0.65 \\
ITGV \% pred & $55 \pm 16$ & $89 \pm 16$ & $<0.001$ \\
FVC \% pred & $64 \pm 24$ & $107 \pm 18$ & $<0.001$ \\
FEV1 \% pred & $62 \pm 20$ & $100 \pm 14$ & $<0.001$ \\
FEV1/FVC \% & $81 \pm 8$ & $76 \pm 3$ & 0.01 \\
RV \% pred & $59 \pm 19$ & $114 \pm 22$ & $<0.001$ \\
TLC \% pred & $55 \pm 16$ & $100 \pm 12$ & $<0.001$ \\
PEF \% pred & $92 \pm 26$ & $98 \pm 21^{\#}$ & 0.5 \\
\hline
\end{tabular}

Data are presented as $n$, median (interquartile range) or mean $+S D$, unless otherwise stated. ILD: interstitial lung disease; BMI: body mass index; ITGV: intrathoracic gas volume (estimating functional residual capacity); $\%$ pred: \% predicted; FVC: forced vital capacity; FEV1: forced expiratory volume in $1 \mathrm{~s}$; RV: residual volume; TLC: total lung capacity; PEF: peak expiratory flow. ${ }^{\#}: \mathrm{n}=12$. 


\begin{tabular}{|c|c|c|c|}
\hline & ILD & Controls & $p$-value \\
\hline Distance $\mathrm{m}$ & $383(285-454)$ & 552 (503-598) & $<0.001$ \\
\hline Oxygen L. $\min ^{-1}$ & $1(0-3)$ & $0(0-0)$ & $<0.001$ \\
\hline \multicolumn{4}{|l|}{ Dyspnoea } \\
\hline Rest & 0 (0-0.5) & $0(0-0)$ & 0.005 \\
\hline Post-exercise & $3.25(1-7.5)$ & $0(0-0.25)$ & $<0.001$ \\
\hline \multicolumn{4}{|l|}{ Limb discomfort } \\
\hline Rest & $0(0-0)^{\#}$ & $0(0-0)^{\oplus}$ & 0.44 \\
\hline Post-exercise & $0.25(0-2.75)$ & $0(0-0)$ & 0.045 \\
\hline \multicolumn{4}{|l|}{$\mathrm{pH}$} \\
\hline Rest & $7.42(7.41-7.44)$ & $7.41(7.40-7.43)$ & 0.1 \\
\hline Post-exercise & $7.42 \pm 0.04^{+}$ & $7.41 \pm 0.04^{+}$ & 0.2 \\
\hline \multicolumn{4}{|l|}{$\mathrm{SaO}_{2} \%$} \\
\hline Rest & $95(94-96)$ & 97 (96-98) & $<0.001$ \\
\hline Post-exercise & $83(76-90)^{+}$ & 97 (96-98) & $<0.001$ \\
\hline \multicolumn{4}{|l|}{$\mathrm{PaO}_{2} \mathrm{mmHg}$} \\
\hline Rest & $73(81-63)$ & $76(72-82)$ & 0.10 \\
\hline Post-exercise & $56(45-69)^{+}$ & $86(81-90)$ & $<0.001$ \\
\hline \multicolumn{4}{|l|}{$\mathrm{PaCO}_{2} \mathrm{mmHg}$} \\
\hline Rest & $37(34-42)$ & $37(35-40)$ & 0.8 \\
\hline Post-exercise & $37(33-42)^{+}$ & $37(34-39)$ & 0.94 \\
\hline
\end{tabular}

Data are presented as median (interquartile range) or mean \pm SD, unless otherwise stated. ILD: interstitial lung disease; $\mathrm{SaO}_{2}$ : arterial oxygen saturation; $\mathrm{PaO}_{2}$ : arterial oxygen tension; $\mathrm{PaCO}_{2}$ : arterial carbon dioxide tension. ${ }^{\#}: \mathrm{n}=18 ;{ }^{\oplus}: \mathrm{n}=12 ;{ }^{+}: \mathrm{n}=23$.

\section{Discussion}

The main finding of this study was that, in the investigated cohort of ILD patients, volitionally assessed global respiratory muscle strength was preserved, while results from nonvolitional measurements point towards a notable reduction in diaphragmatic muscle strength.

\section{Respiratory muscle function: current findings in light of the available body of literature} Investigation of respiratory muscle function in ILD patients by the use of volitional techniques has led to contradictory reports in the literature: some studies have observed impaired inspiratory muscle strength (i.e. reduced PImax) [28-30], while others have reported preserved PImax (as in the present study) [3, 8, 9, 31]. These disparate findings might be explained by the fact that the degree of restrictive lung function impairment varies greatly amongst ILD patients (mean vital capacity ranged from $63 \%$ to $77 \%$ predicted), whereby disease severity probably represents an important confounding factor for the interpretation of data gained by volitional measurements. Interestingly, the current data revealed no difference in expiratory muscle strength between ILD patients and healthy controls, despite the fact that TLC was markedly lower in the former group. This finding might suggest that global expiratory muscle function in ILD patients is not only comparable with that of healthy subjects but might even be enhanced in this cohort. It is of note that earlier work in ILD patients also revealed that PEmax values were not reduced when compared with healthy controls [3, 31].

\section{Pathophysiological considerations}

Several pathophysiological mechanisms responsible for the alteration in respiratory muscle function in ILD patients have been proposed. First, avoidance of activities provoking dyspnoea results in physical deconditioning and muscle wasting [6]. In addition, the systemic inflammatory state due to elevated levels of pro-inflammatory cytokines might also impair muscle function [32]. In these "systemic" scenarios, a similar impairment of both peripheral skeletal and respiratory muscles might occur. It is of note that the current study revealed that peripheral muscle strength (hand-grip force) remained unchanged, while respiratory muscle strength ( $\mathrm{Tw} P \mathrm{mo}$ and $\mathrm{Tw} P \mathrm{di}$ ) was significantly impaired in ILD patients. However, a retrospective study based on predicted values for maximal voluntary contraction of the quadriceps muscle without a control group suggested peripheral muscle dysfunction in ILD patients [31].

Secondly, immunosuppressive agents might alter (respiratory) muscle function. Corticosteroids are particularly known to cause both peripheral and respiratory myopathy [33]. However, WANG et al. [34] 


\section{TABLE 3 Muscle function}

\begin{tabular}{|c|c|c|c|}
\hline & ILD & Controls & p-value \\
\hline PImax kPa & $9.3 \pm 3.4$ & $8.7 \pm 2.8$ & 0.51 \\
\hline PEmax $\mathrm{kPa}$ & $14.2 \pm 5.5$ & $15.8 \pm 4.7$ & 0.30 \\
\hline$P_{0.1} \mathrm{kPa}$ & $0.3(0.3-0.5)$ & $0.2(0 . \overline{1}-0.3)$ & 0.01 \\
\hline P0.1/PImax \% & $4.0(2-7)$ & $2.0(0-3)$ & 0.006 \\
\hline$f R L \cdot \min ^{-1}$ & $21 \pm 6^{\#}$ & $18 \pm 5$ & 0.04 \\
\hline$V T \mathrm{~L}$ & $0.73 \pm 0.28^{\#}$ & $0.75 \pm 0.27$ & 0.80 \\
\hline$P_{0.1} \times \mathrm{ti}_{\mathrm{i}} / \mathrm{VT} \mathrm{kPa} \cdot \mathrm{s} \cdot \mathrm{L}^{-1}$ & $0.56(0.4-0.61)^{\#}$ & $0.38(0 . \overline{28}-0.51)^{\pi}$ & 0.049 \\
\hline SnPna kPa & $8.6(7.3-9.8)$ & $8.3(6.3-10.3)$ & 0.99 \\
\hline TwPmo kPa & $0.86 \pm 0.4$ & $1.32 \pm 0.4$ & $<0.001$ \\
\hline TwPoes kPa & $0.92 \pm 0.4^{+}$ & $1.15 \pm 0.3^{\S}$ & 0.17 \\
\hline TwPga KPa & $-0.47 \pm 0.3^{+}$ & $-0.77 \pm 0.2^{\S}$ & 0.01 \\
\hline TwPdi kPa & $1.32 \pm 0.6^{+}$ & $1.88 \pm 0.5^{\S}$ & 0.02 \\
\hline ttrig-max ms & $129 \pm 16$ & $139 \pm 11$ & 0.049 \\
\hline \multicolumn{4}{|l|}{ Hand-grip force } \\
\hline Right kPa & $107 \pm 20^{f}$ & $116 \pm 40^{\# \#}$ & 0.66 \\
\hline Left kPa & $103 \pm 25^{f}$ & $108 \pm 35^{\# \#}$ & 0.76 \\
\hline
\end{tabular}

Data are presented as median (interquartile range) or mean \pm SD, unless otherwise stated. ILD: interstitial lung disease; PImax: maximal inspiratory mouth occlusion pressure; PEmax: maximal expiratory mouth occlusion pressure; P0.1: mouth occlusion pressure $0.1 \mathrm{~s}$ after the onset of inspiration; fR: respiratory frequency; $V_{T}$ : tidal volume; ti: inspiratory time; SnPna: sniff nasal pressure; TwPmo: twitch mouth pressure; TwPoes: twitch oesophageal pressure; TwPga: twitch gastric pressure; TwPdi: twitch transdiaphragmatic pressure; trig-max: time between trigger impulse and maximum TwPmo. ${ }^{\#}: \mathrm{n}=20 ;{ }^{\uparrow}: \mathrm{n}=17 ;^{+}: \mathrm{n}=10 ;{ }^{\S}: \mathrm{n}=11{ }^{f}: \mathrm{f}=22 ;{ }^{\# \#}: \mathrm{n}=5$.

showed that respiratory muscle strength remained unaltered when $\leqslant 20 \mathrm{mg}$ of prednisolone was administered per day. Interestingly, the above-mentioned ILD cohort with peripheral muscle dysfunction did not receive corticosteroid treatment [31]. Again, the current study revealed that peripheral muscle strength did not change in ILD patients despite a significant reduction in diaphragmatic strength.

Thirdly, the potential presence of polyneuropathy in the ILD cohort might have impaired respiratory muscle function. This is of special importance to the twitch pressure results, since neuropathic processes occurring secondarily to axonal loss and/or demyelination could reduce twitch pressure values. Importantly, none of the ILD patients included in this study suffered from the presence of polyneuropathy according to their medical history or upon physical examination, and no associated symptoms were reported by the patients. Additionally, trig-max as a surrogate of phrenic nerve conduction time was not prolonged in ILD patients and did not differ from that of control subjects. For these reasons, relevant demyelination of the phrenic nerves in ILD patients is unlikely, whereas axonal loss cannot be ruled out with any certainty. Further studies are therefore needed to investigate this issue.

Finally, mechanical diaphragmatic restraints (i.e. stiffness of the lung) cause increased work of breathing $[28,35]$. This could either train the respiratory muscles [28] or cause chronic overload [36].

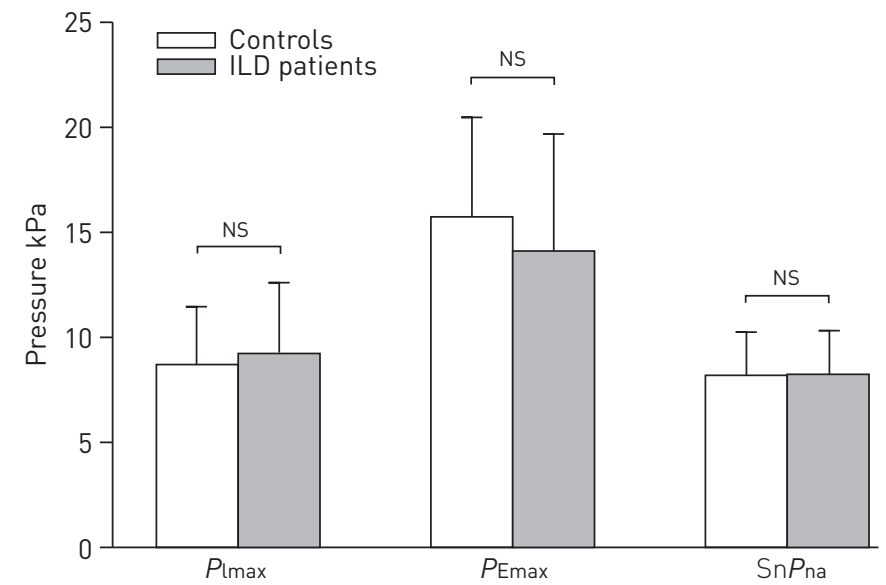

FIGURE 1 Parameters for volitionally assessed maximal inspiratory mouth occlusion pressure (PImax), maximal expiratory mouth occlusion pressure (PEmax) and sniff nasal pressure $(\mathrm{SnPna})$ in interstitial lung disease (ILD) patients and matched controls. NS: nonsignificant. Error bars indicate $95 \%$ confidence interval of the mean. 
FIGURE 2 Nonvolitionally assessed twitch mouth and transdiaphragmatic pressure ( $\mathrm{Tw} P$ mo and TwPdi, respectively) in interstitial lung disease (ILD) patients and matched controls. Error bars indicate $95 \%$ confidence interval of the mean.

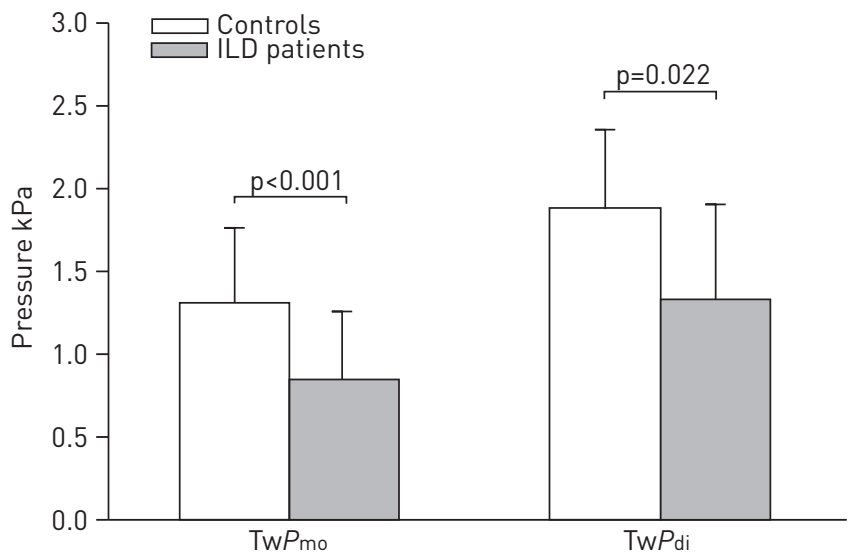

\section{Respiratory drive and load imposed on inspiratory muscles in ILD patients}

The present study and several previous studies have shown that central respiratory drive (estimated by $P_{0.1}$ ) is elevated in ILD patients $[9,29,37]$. However, diaphragmatic electromyography revealed that $P_{0.1}$ does not adequately reflect the neural output to the inspiratory muscles in ILD patients [30]. Thus, care must be taken when respiratory drive is estimated by $P_{0.1}$ in the presence of inspiratory muscle dysfunction [30]. Indeed, inspiratory muscle dysfunction was detected in ILD patients in the present study, as reflected by the reduced twitch pressures.

TABLE 4 Subgroup analysis of interstitial lung disease patients

CCL18

p-value

\begin{tabular}{|c|c|c|c|}
\hline & & \\
\hline & $<150 \mathrm{ng} \cdot \mathrm{mL}^{-1}$ & $>150 \mathrm{ng} \cdot \mathrm{mL}^{-1}$ & \\
\hline Subjects & 10 & 13 & \\
\hline Male/female & $7 / 3$ & $13 / 0$ & 0.07 \\
\hline FVC \% pred & $69 \pm 25$ & $60 \pm 23$ & 0.38 \\
\hline TLC $\%$ pred & $62(51-74)$ & $57(37-77)$ & 0.59 \\
\hline FEV $1 \%$ pred & $61+20$ & $62+21$ & 0.93 \\
\hline FEV1/FVC \% & $80 \pm 6$ & $82 \pm 9$ & 0.56 \\
\hline PImax kPa & $6.9 \pm 2.4$ & $10.9 \pm 2.9$ & 0.003 \\
\hline P0.1 kPa & $0.39 \pm 0.2$ & $0.36 \pm 0.22$ & 0.87 \\
\hline SnPna kPa & $8.1 \pm 2$ & $8.5 \pm 2.2$ & 0.78 \\
\hline TwPmo kPa & $0.96 \pm 0.5$ & $0.79 \pm 0.4$ & 0.22 \\
\hline ttrig-max ms & $130 \pm 14$ & $128 \pm 18$ & 0.83 \\
\hline \multicolumn{3}{|l|}{ Dyspnoea } & 0.16 \\
\hline Rest & $0(0-0.5)$ & $0(0-0.5)$ & 0.77 \\
\hline Post-exercise & $2(0-7)$ & $5(2-8)$ & 0.21 \\
\hline \multicolumn{4}{|l|}{$\mathrm{pH}$} \\
\hline Rest & $7.43 \pm 0.02$ & $7.42 \pm 0.02$ & 0.78 \\
\hline Post-exercise & $7.43 \pm 0.02$ & $7.43 \pm 0.03$ & 0.91 \\
\hline \multicolumn{4}{|l|}{$\mathrm{PaO}_{2} \mathrm{mmHg}$} \\
\hline Rest & $68 \pm 11$ & $60 \pm 15$ & 0.15 \\
\hline Post-exercise & $76 \pm 10$ & $55 \pm 14$ & 0.51 \\
\hline \multicolumn{4}{|l|}{$\mathrm{PaCO}_{2} \mathrm{mmHg}$} \\
\hline Rest & $39 \pm 7$ & $38 \pm 4$ & 0.97 \\
\hline Post-exercise & $40+8$ & $38+5$ & 0.52 \\
\hline
\end{tabular}

Data are presented as $\mathrm{n}$, mean \pm SD or median (interquartile range), unless otherwise stated. FVC: forced vital capacity; \% pred: \% predicted; TLC: total lung capacity; FEV1: forced expiratory volume in $1 \mathrm{~s}$; PImax: maximal inspiratory mouth occlusion pressure; $P 0.1$ : mouth occlusion pressure $0.1 \mathrm{~s}$ after the onset of inspiration; SnPna: sniff nasasl pressure; TwPmo: twitch mouth pressure; ttrig-max: time between trigger impulse and maximum TwPmo; $\mathrm{PaO}_{2}$ : arterial oxygen tension; $\mathrm{PaCO}_{2}$ : arterial carbon dioxide tension. 
The present study revealed that there is an increased load on the inspiratory muscles in ILD patients. Along with rapid shallow breathing (i.e. high breathing frequency and low tidal volume), which is common in ILD patients $[36,38]$, the development of force by the inspiratory muscles is impaired, and this contributes to the increase in breathlessness [39]. Exercise impairment in ILD patients has been mainly attributed to impaired gas exchange, pathological pulmonary circulation and peripheral muscle weakness $[6,31]$. The current results, however, suggest that impaired respiratory muscle function might also play an important role in these processes.

\section{Biomarker}

Increased CCL18 plasma levels (i.e. $>150 \mathrm{ng} \cdot \mathrm{mL}^{-1}$ ) predict poor survival in patients with IPF [11]. In the present study, increased CCL18 levels were linked to an elevated $P_{0.1}$ and reduced 6-min walking distance. This is of particular importance, given that the $6 \mathrm{MWT}$ has been postulated as a valid end-point in clinical ILD trials [40].

Interestingly, increased CCL18 levels were also associated with higher PImax values. This finding is surprising, however, as a higher risk of death implies that respiratory muscle function is more severely impaired. However, the pathophysiological changes in ILD that increase the load on the inspiratory muscles might actually impart a training effect on the respiratory muscles, as proposed by DE TroYer and YERNAULT [28]. Once the disease progresses further, however, this effect is suspected to fail, as suggested by the occurrence of hypercapnic respiratory failure [35].

\section{Critique of methods}

There are certain limitations of the current study that need to be addressed. First, instead of focusing on one single distinct type of ILD, this study, like several others [28, 29, 36, 37], was comprised of ILD patients with miscellaneous aetiologies. This needs to be taken into account when interpreting the current findings, as (respiratory) muscle impairment can vary amongst patients with different aetiologies. This is of special importance with respect to the underlying conditions known to affect the (respiratory) muscles per se (e.g. inflammatory myopathies such as dermato-polymyositis and others [41]). To this end, the current study did not include ILD patients with inflammatory myopathies. The majority of ILD was suggested to predominantly affect the lung (parenchyma) rather than the respiratory muscles [2]. However, the present results do indicate that respiratory muscle impairment in ILD might have been underestimated in the past.

Secondly, peripheral muscle strength was solely assessed by volitional hand-grip force, which, in line with previous findings [31], was not reduced in ILD patients. In contrast, volitionally assessed quadriceps muscle strength was reported to be reduced in these patients [31]. Detailed assessment of peripheral muscle function was beyond the scope of the present study; thus, nonvolitional assessment of peripheral muscle strength (e.g. magnetic femoral nerve stimulation) should be incorporated into future studies to verify these contradictory preliminary observations.

\section{Conclusion}

This study indicates that diaphragmatic force generation might be significantly impaired in the currently investigated cohort of ILD patients, while global respiratory muscle strength is preserved and the load imposed on the inspiratory muscles is increased. Future studies should therefore aim to assess the potential impact of impaired respiratory muscle function on morbidity and mortality in ILD patients.

\section{Acknowledgements}

All participants are acknowledged for their time and effort. We would like to thank Claudia Schmoor (Biometry and Data Management, Center of Clinical Trials, University Medical Center Freiburg, Freiburg, Germany) and Dieter Hauschke (Institute of Medical Biometry and Medical Informatics, University of Freiburg, Freiburg, Germany) for biometric consulting, Gernot Zissel (University Hospital Freiburg, Dept of Pneumology, Freiburg, Germany) for assistance with laboratory measurements and Sandra Dieni for helpful comments on the manuscript prior to submission.

\section{References}

1 American Thoracic Society/European Respiratory Society International Multidisciplinary Consensus Classification of the Idiopathic Interstitial Pneumonias. Am J Respir Crit Care Med 2002; 165: 277-304.

2 Raghu G, Collard HR, Egan JJ, et al. An official ATS/ERS/JRS/ALAT statement: idiopathic pulmonary fibrosis: evidence-based guidelines for diagnosis and management. Am J Respir Crit Care Med 2011; 183: 788-824.

3 O'Donnell DE, Chau LK, Webb KA. Qualitative aspects of exertional dyspnea in patients with interstitial lung disease. J Appl Physiol 1998; 84: 2000-2009.

4 Baydur A, Alsalek M, Louie SG, et al. Respiratory muscle strength, lung function, and dyspnea in patients with sarcoidosis. Chest 2001; 120: 102-108.

5 Kabitz H, Lang F, Walterspacher S, et al. Impact of impaired inspiratory muscle strength on dyspnea and walking capacity in sarcoidosis. Chest 2006; 130: 1496-1502. 
Holland AE. Exercise limitation in interstitial lung disease - mechanisms, significance and therapeutic options. Chron Respir Dis 2010; 7: 101-111.

7 Marcellis RGJ, Lenssen AF, Elfferich MDP, et al. Exercise capacity, muscle strength and fatigue in sarcoidosis. Eur Respir J 2011; 38: 628-634.

8 Nishimura Y, Hida W, Taguchi O, et al. Respiratory muscle strength and gas exchange in neuromuscular diseases: comparison with chronic pulmonary emphysema and idiopathic pulmonary fibrosis. Tohoku J Exp Med 1989; 159: 57-68.

9 Garcia-Rio F, Pino JM, Ruiz A, et al. Accuracy of noninvasive estimates of respiratory muscle effort during spontaneous breathing in restrictive diseases. J Appl Physiol 2003; 95: 1542-1549.

10 ATS/ERS statement on respiratory muscle testing. Am J Respir Crit Care Med 2002; 166: 518-624.

11 Prasse A, Pechkovsky DV, Toews GB, et al. CCL18 as an indicator of pulmonary fibrotic activity in idiopathic interstitial pneumonias and systemic sclerosis. Arthritis Rheum 2007; 56: 1685-1693.

12 Magnussen H, Kirsten AM, Kohler D, et al. Leitlinien zur Langzeit-Sauerstofftherapie. Deutsche Gesellschaft Für Pneumologie und Beatmungsmedizin e.V. [Guidelines for the long-term oxygen therapy. German Society for Pneumology and Respiratory Medicine.]. Pneumologie 2008; 62: 748-756.

13 Miller MR, Hankinson J, Brusasco V, et al. Standardisation of spirometry. Eur Respir J 2005; 26: 319-338.

14 Matthys H, Zaiss A, Theissen J, et al. Definitionen, Soll- und Meßwerte zur Diagnose obstruktiver, restriktiver sowie gemischter Ventilationsstörungen für die klinische Lungenfunktionsdiagnostik [Definition, normal reference and measured values to diagnose obstructive, restrictive and mixed ventilatory defects for clinical lung-function evaluation]. Atemw-Lungenkrkh 1995; 21: 130-138.

15 Macintyre N, Crapo RO, Viegi G, et al. Standardisation of the single-breath determination of carbon monoxide uptake in the lung. Eur Respir J 2005; 26: 720-735.

16 ATS statement: guidelines for the six-minute walk test. Am J Respir Crit Care Med. 2002; 166: 111-117.

17 Borg GA. Psychophysical bases of perceived exertion. Med Sci Sports Exerc 1982; 14: 377-381.

18 Whitelaw WA, Derenne JP. Airway occlusion pressure. J Appl Physiol 1993; 74: 1475-1483.

19 Whitelaw WA, Derenne JP, Milic-Emili J. Occlusion pressure as a measure of respiratory center output in conscious man. Respir Physiol 1975; 23: 181-199.

20 Windisch W, Hennings E, Sorichter S, et al. Peak or plateau maximal inspiratory mouth pressure: which is best? Eur Respir J 2004; 23: 708-713.

21 Windisch W, Kabitz H, Sorichter S. Influence of different trigger techniques on twitch mouth pressure during bilateral anterior magnetic phrenic nerve stimulation. Chest 2005; 128: 190-195.

22 Kabitz H, Walker D, Walterspacher S, et al. Controlled twitch mouth pressure reliably predicts twitch esophageal pressure. Respir Physiol Neurobiol 2007; 156: 276-282.

23 Mador MJ, Magalang UJ, Kufel TJ. Twitch potentiation following voluntary diaphragmatic contraction. Am J Respir Crit Care Med 1994; 149: 739-743.

24 Mills GH, Kyroussis D, Hamnegard $\mathrm{CH}$, et al. Bilateral magnetic stimulation of the phrenic nerves from an anterolateral approach. Am J Respir Crit Care Med 1996; 154: 1099-1105.

25 Mador MJ, Khan S, Kufel TJ. Bilateral anterolateral magnetic stimulation of the phrenic nerves can detect diaphragmatic fatigue. Chest 2002; 121: 452-458.

26 Kabitz H, Schwoerer A, Bremer H, et al. Impairment of respiratory muscle function in pulmonary hypertension. Clin Sci (Lond) 2008; 114: 165-171.

27 Kabitz H, Sonntag F, Walker D, et al. Diabetic polyneuropathy is associated with respiratory muscle impairment in type 2 diabetes. Diabetologia 2008; 51: 191-197.

28 de Troyer A, Yernault JC. Inspiratory muscle force in normal subjects and patients with interstitial lung disease. Thorax 1980; 35: 92-100.

29 DiMarco AF, Kelsen SG, Cherniack NS, et al. Occlusion pressure and breathing pattern in patients with interstitial lung disease. Am Rev Respir Dis 1983; 127: 425-430.

30 Gorini M, Spinelli A, Ginanni R, et al. Neural respiratory drive and neuromuscular coupling during $\mathrm{CO}_{2}$ rebreathing in patients with chronic interstitial lung disease. Chest 1989; 96: 824-830.

31 Nishiyama O, Taniguchi H, Kondoh Y, et al. Quadriceps weakness is related to exercise capacity in idiopathic pulmonary fibrosis. Chest 2005; 127: 2028-2033.

32 Prasse A, Muller-Quernheim J. Non-invasive biomarkers in pulmonary fibrosis. Respirology 2009; 14: 788-795.

33 Dekhuijzen PN, Decramer M. Steroid-induced myopathy and its significance to respiratory disease: a known disease rediscovered. Eur Respir J 1992; 5: 997-1003.

34 Wang YM, Zintel T, Vasquez A, et al. Corticosteroid therapy and respiratory muscle function in humans. Am Rev Respir Dis 1991; 144: 108-112.

35 Nava S, Rubini F. Lung and chest wall mechanics in ventilated patients with end stage idiopathic pulmonary fibrosis. Thorax 1999; 54: 390-395.

36 Javaheri S, Sicilian L. Lung function, breathing pattern, and gas exchange in interstitial lung disease. Thorax 1992; 47: 93-97.

37 Scott GC, Burki NK. The relationship of resting ventilation to mouth occlusion pressure. An index of resting respiratory function. Chest 1990; 98: 900-906.

38 Renzi G, Milic-Emili J, Grassino AE. The pattern of breathing in diffuse lung fibrosis. Bull Eur Physiopathol Respir 1982; 18: 461-472.

39 Burdon JG, Killian KJ, Jones NL. Pattern of breathing during exercise in patients with interstitial lung disease. Thorax 1983; 38: 778-784.

40 du Bois R, Weycker D, Albera C, et al. 6-minute walk test in idiopathic pulmonary fibrosis: test validation and minimal clinically important difference. Am J Respir Crit Care Med 2011; 183: 1231-1237.

41 Teixeira A, Cherin P, Demoule A, et al. Diaphragmatic dysfunction in patients with idiopathic inflammatory myopathies. Neuromuscul Disord 2005; 15: 32-39. 